Federal Reserve Bank of Minneapolis

Research Department

\title{
The Economics of Split-Ticket Voting in Representative Democracies
}

\author{
V. V. Chari, Larry E. Jones, \\ and Ramon Marimon* \\ Working Paper 582D
}

June 1997

\begin{abstract}
In U.S. elections, voters often vote for candidates from different parties for president and Congress. Voters also express dissatisfaction with the performance of Congress as a whole and satisfaction with their own representative. We develop a model of split-ticket voting in which government spending is financed by uniform taxes but the benefits from this spending are concentrated. While the model generates splitticket voting, overall spending is too high only if the president's powers are limited. Overall spending is too high in a parliamentary system, and our model can be used as the basis of an argument for term limits.
\end{abstract}

*Chari, Federal Reserve Bank of Minneapolis and University of Minnesota; Jones, Northwestern University; Marimon, European University Institute. We thank Rodolfo E. Manuelli, Roger Myerson, Thomas Sargent, seminar participants at a number of places, the editors and referees of the American Economic Review for useful discussions and comments, and the National Science Foundation for financial support. The views expressed herein are those of the authors and not necessarily those of the Federal Reserve Bank of Minneapolis or the Federal Reserve System. 
In this paper, we present a simple economic model to capture certain features of the U.S. political system. A widely held view of the political process in the United States is that people vote for a president and representatives whose preferences are closest to their own. Typically, this view is formalized in theoretical models as the median voter theorem. That is, the president and Congress represent the preferences of the median voter. Three observations call this view into question:

1. There is a substantial amount of split-ticket voting (i.e., voters vote for a candidate from one party in the presidential election and a candidate from another party in the congressional election), and this phenomenon seems to be growing. If parties represent general political philosophies and voters choose candidates solely on the basis of this philosophy, this phenomenon conflicts with the median voter view.

2. When asked, people are highly dissatisfied with the performance of Congress as a whole. For example, the percentage of people saying that they have "a lot of confidence" in the leaders of Congress has averaged around 15 percent over the last 20 years, reaching a low of 9 percent in 1980 (USA Today, 4/1/92).

3. There is a substantial difference in approval ratings of Congress as a whole and those of individual representatives. For example, in surveys from May 1989 to March 1992 conducted by USA Today, the average approval rating for individual representatives by their constituents was 61 percent, while it was only 38 percent for Congress as a whole.

Observations 2 and 3 are in direct conflict with the view that the president's and representatives' actions reflect the preferences of the median voter and therefore conflict with the median voter theorem. A broader literature (see, for example, Dennis C. Mueller 1989 and Peter J. 
Coughlin 1990) models policy choice as the outcome of majority voting when there is one vote on one pair of alternatives. The results of this paper are in stark contrast with the median voter view.

Observation 1 has been extensively documented in the political science literature, for example, by Gary C. Jacobson (1990). (See also Morris P. Fiorina 1991 and Mark A. Zupan 1991.) Moreover, this phenomenon has been on the rise since World War II. For example, while only about 10 percent of the ballots cast in the elections in 1952 were "split," that figure was up to 30 percent by 1988 . Further, while there was only one election between 1856 and 1952 in which the presidency and control of Congress went to different parties (in 1888), this type of split has occurred in 7 of the 11 presidential election years since 1952. (All these elections except the one in 1996 featured a Congress controlled by the Democrats and a Republican president.) During the period from 1876 to 1928, the difference between the Democratic vote for candidates for the House and the Democratic vote for the president averaged 0.19 percent, while this figure was 8.9 percent between 1932 and 1964 and 13.7 percent between 1968 and 1988. This broad pattern is replicated in the states as well. In summary, split-ticket voting is a far-reaching phenomenon that has been growing substantially over the years since World War II. Moreover, the pattern that emerges is one in which Democrats are successful in the more local elections, while Republicans are (relatively) more successful in the more global elections. Even after the 1996 elections (which in some ways do not fit the broad pattern described here), 33 of 50 governors were Republican, while a Republican majority was returned to Congress for the first time in 66 years.

In this paper, we present a series of simple political economy models based entirely on the economics of public policy. The essence of the models is a simple budgetary externality in a noncooperative model of spending determination. This externality arises from two assumptions. One assumption is that government spending is assumed to be geographically dispersed, with benefits going only to those in the district in which the spending occurs. The other assumption is that all 
spending at the federal level is financed through a system of uniform taxes across all districts. These two assumptions imply that voters have quite different incentives for choosing representatives and the president. Because an individual representative has little effect on aggregate spending, voters elect representatives who are the most effective at bringing spending into their home districts and show little regard to the effect their choices have on overall spending. Thus, representatives act as lobbyists for their home districts. In choosing the president, all voters in the model prefer that the president be a fiscal conservative to limit congressional exploitation. The differing roles of representatives and the president give the observations noted above as equilibrium outcomes of our model.

In a sense, this result amounts to a formalization of the widely held view that voters in the United States elect fiscally liberal representatives and conservative presidents to restrain them. Another part of this widely held view is that overall government spending is too high. We show that this part does not necessarily hold. In fact, if choices are interior, the equilibrium outcome is efficient (in the symmetric case). In equilibrium, voters use the system of fiscal checks and balances in their choices for a president and representatives in such a way that the resulting inefficiencies exactly offset each other. However, if the size of the legislature is large and the power of the president is limited in the budgetary process, overall spending will be too high. Similarly, if the president is also the deciding factor on other, say, social, issues, this pattern of offsetting inefficiencies does not work. Indeed, we show that including other policy issues (like abortion or foreign policy) in the analysis alters our results concerning the type of the president (i.e., the president need not be fiscally conservative in the extreme), but does not alter the characterization of the types of representatives. When other policy issues are included, voters choose a compromise, with spending too high and foreign policy too conservative in equilibrium.

Although the model we analyze is purely static in nature, it is also suggestive of the time series observations on the coincidence of the increase in split-ticket voting and the level of overall 
spending noted above. (Indeed, Jacobson places the time of the change as the beginning of the New Deal legislation.) On the one hand, if overall spending is low for some exogenous reason, the severity of the budgetary externality is slight and there is little incentive for split-ticket voting. On the other hand, as spending is increased, the budgetary externality becomes more severe, giving rise to more split-ticket voting.

An implication of our analysis is that voting choices may be very poor indicators of the true preferences of voters. Further, our analysis suggests that the choices of representatives may be quite different from those of the median voter. One can actually learn more from the models we examine. In particular, in one of the models, the president's preferences over spending as a whole agree with those of the voters. In contrast, representatives are much more tolerant of spending than the voters who elect them.

This paper is related to a large and growing literature in political science and political economy. ${ }^{1}$ Rather than survey this literature, we explore our paper's connections with some closely related work. Jacobson (1990) presents the first version of the basic idea we exploit in our formal model. This idea is that the structure of the budget-making process presents voters with what Zupan (1991) terms a prisoner's dilemma in the choice of representatives. It is worth pointing out that our theory deals with split-ticket voting between fiscal conservatives and fiscal liberals, while the evidence of Jacobson and Zupan deals with split-ticket voting between Republicans and Democrats. Nonetheless, their evidence supports the equilibrium outcomes of our model. For example, Zupan presents evidence that Democrats have larger staffs in their home districts than in Washington compared to Republicans. He uses this evidence to argue that Democratic representatives engage in benefit-seeking activities that are more local.

To our knowledge, the only other formal model of split-ticket voting is that in Alberto Alesina and Rosenthal $(1989,1996)$. (See also Alesina, Fiorina, and Rosenthal 1991.) Those studies consider 
a model where there are two parties with fixed positions. Representatives and the president are chosen from one of these two parties. Voters have single-peaked preferences, and the positions of the two parties lie on either side of the ideal point of the median voter. Thus, the median voter uses split-ticket voting as a means of balancing the positions of the two parties to achieve a more desirable outcome. Alesina and Rosenthal use this model to obtain the result that in midterm elections, the president's party typically loses seats in the House. While the equilibrium outcomes in the papers cited above and this one are similar, the fact that party positions are endogenous in our model (as in David P. Baron 1993) implies that the forces at work are quite different.

This paper is also related to the literature on strategic delegation. (See Kenneth Rogoff 1985, Chaim Fershtman and Kenneth L. Judd 1987, Torsten Persson and Guido Tabellini 1990, 1994, and Fershtman and Ehud Kalai 1993.) An interesting feature of the detailed bargaining model we examine is that even if all voters are identical, they elect representatives whose preferences are systematically different from their own. This occurs even if candidates are available who have exactly the same preferences as the voters. In our models, this feature arises because the bargaining game among representatives over the budget induces a Bertrand-style competition in the choice of types of representatives by the voters in different districts. In particular, voters attempt to increase the probability that their district is included in the winning coalition by choosing a representative who values public spending more than the representatives in other districts. This form of competition leads to an equilibrium in which all representatives are not merely different from voters, but they are at the extreme in terms of their preferences for public spending. The deeper forces underlying this result are the budgetary externality and the assumption that representatives' types (rather than voters' preferences) determine outcomes. Because of these forces, it is likely that other models with these features will produce strategic delegation with systematic misrepresentation. In contrast to the models in Rogoff (1985) and Persson and Tabellini (1990, 1994), where strategic delegation arises because 
of a time consistency problem, it arises here because of the free rider problem induced by the budgetary externality.

It is also worth pointing out that, in contrast to most of the voting literature, heterogeneity in preferences among voters within a district plays no role in our results. Indeed, our split-ticket voting results hold even if there is no heterogeneity within a district. Rather, our results are driven by the heterogeneity in preferences across districts in combination with the budgetary externality mentioned above.

Given these results, the fact that some voters split their ballots-that is, choose presidential and congressional candidates of different parties-is not a puzzle. Rather, the puzzle is that not all voters do this. While we do not solve this puzzle in this paper, we conjecture that some of our deliberately stark assumptions drive the results. For example, we assume that all residents in a district benefit from district-specific spending. Heterogeneity in preferences along this dimension may well solve this puzzle. Furthermore, we show that voters' concerns over global public goods or global issues, such as foreign policy, may affect their choice of a president. Interestingly, however, these concerns do not affect their choices of representatives.

We begin with a general approach in Section I. There, rather than present a detailed analysis of the bargaining between the president and the congress over the budget, we show that if the outcomes of this bargaining satisfy a set of monotonicity, symmetry, and concavity conditions, voters elect a fiscal conservative as president and fiscal liberals as their representatives. Next, in Section II, we develop a model of the bargaining process for determining the budget, which is based on the approach of Baron and John Ferejohn (1989). We adapt this model to include a president and an endogenous the level of aggregate spending. This model takes a step toward identifying the types of characteristics for representatives that are useful in coalition building. 
In Section III, we use two examples to illustrate the role played by our assumptions and to extend the model to a discussion of related issues. In one example, we show that without further assumptions, the budgetary externality leads to more spending in parliamentary systems than in presidential ones. In the other example, we use our model to analyze the benefits and costs of term limits. Because term limits are commitments not to reelect incumbents, from a decision-theoretic perspective, term limits are at best unnecessary and are potentially harmful. (This point of view is discussed in Gary Becker 1990.) Because we consider a strategic formulation, however, this type of restriction on future strategies can raise the welfare of voters. The models analyzed in Sections I and II suggest two approaches to understanding voter support for term-limit legislation in spite of the potential costs. One approach, a straightforward generalization of the model analyzed in Section I, shows that if aggregate spending is increasing in average tenure, term limits can be socially beneficial, even though no district has the incentive to unilaterally impose them. (See also Andrew R. Dick and John R. Lott, Jr., 1993 for an influence-peddling approach to this problem and W. Robert Reed and D. Eric Schansberg 1994.) This will be the case if increased average tenure increases the average effectiveness of a representative as a lobbyist for the home district, for example. The other approach concerns the ability to dynamically select effective lobbyists at the polls. To address this issue, we analyze a simple model in which the fiscal types of representatives are unknown at the time of election but, in equilibrium, are revealed through the budgetary process. This selection effect leads to the reelection of representatives who are more fiscally liberal than average and, hence, makes a case for term limits.

\section{A General Model}

In this section, we describe a general model of split-ticket voting.
A. Economy 
There are $\mathrm{N}$ districts. There is a continuum of identical voters in each district with population normalized to one. Each voter in district $\mathrm{n}$ has preferences over private consumption $\mathrm{c}_{\mathrm{n}}$ and government spending in this district $g_{n}$, given by $u\left(g_{n}, c_{n}\right)$, where $u(\bullet, \bullet)$ is strictly concave, increasing, and differentiable and where private consumption and government spending are normal goods. ${ }^{2}$ Each voter has an endowment of the private consumption good of $y$.

Production of each unit of government spending requires one unit of taxes on the private good. We assume that taxes for all voters are lump-sum and equal.

Thus, a balanced budget requires that

$$
\tau=(1 / N) \sum_{n=1}^{N} g_{n}
$$

and

$$
\mathrm{c}_{\mathrm{n}}=\mathrm{y}-\tau
$$

\section{B. Elections}

In each district, one local representative is chosen in an election. Voters in each district also take part in an at-large election for a president. Let $\gamma_{i} \in\left[\gamma_{\ell}, \gamma_{h}\right], \gamma_{\ell}<1<\gamma_{h}$, denote the type of the local representative for district $i$, and let $\gamma_{P} \in\left[\gamma_{e}, \gamma_{h}\right]$ denote the type of the president. One interpretation of the types is that high $\gamma$ 's correspond to a high level of public spending (relative to the population as a whole). We focus on this interpretation in Section II. An alternative interpretation of the types of the representatives is that they represent lobbying ability with higher $\gamma$ 's corresponding to higher ability.

Government spending in each district depends on the mix of types (of both local representatives and the president) chosen in the elections. Let

$$
\mathrm{g}_{\mathrm{n}}=\phi_{\mathrm{n}}\left(\gamma_{1}, \ldots, \gamma_{\mathrm{N}} ; \gamma_{\mathrm{P}}\right)
$$


denote this dependency, and assume that $\phi_{n}$ is differentiable. The function $\phi_{n}$ represents the outcome of the complicated process of bargaining and logrolling both among representatives and between representatives and the president.

Voters' payoffs as a function of the types chosen for both representatives and the president are given by

$$
\mathrm{U}_{\mathrm{n}}=\mathrm{u}\left(\phi_{\mathrm{n}}\left(\gamma ; \gamma_{\mathrm{P}}\right), \mathrm{y}-(1 / \mathrm{N}) \sum_{\mathrm{k}=1}^{\mathrm{N}} \phi_{\mathrm{k}}\left(\gamma ; \gamma_{\mathrm{P}},\right)\right)
$$

C. Equilibrium

Define the most preferred type (of both the local representative and the president) for a voter in district $n$, given the types of other districts denoted $\Gamma_{n}\left(\gamma_{-n}\right)$, by

$$
\left(\Gamma_{\mathrm{n}}^{\mathrm{C}}\left(\gamma_{-\mathrm{n}}\right), \Gamma_{\mathrm{n}}^{\mathrm{P}}\left(\gamma_{-\mathrm{n}}\right)\right)=\underset{\gamma_{\mathrm{n}}, \gamma_{\mathrm{p}}}{\arg \max } \mathrm{u}\left(\phi_{\mathrm{n}}\left(\gamma_{-\mathrm{n}}, \gamma_{\mathrm{n}} ; \gamma_{\mathrm{P}}\right), \mathrm{y}-(1 / \mathrm{N}) \sum_{\mathrm{k}} \phi_{\mathrm{k}}\left(\gamma_{-\mathrm{n}}, \gamma_{\mathrm{n}} ; \gamma_{\mathrm{P}}\right)\right)
$$

We assume that each voter votes for his or her most preferred type for representative and president given the types of representatives from other districts.

An equilibrium is then a vector of types $\left(\gamma_{1}, \ldots, \gamma_{n} ; \gamma_{p}\right)$ so that, for all $n$,

(6) $\quad \gamma_{n} \in \Gamma_{n}^{C}\left(\gamma_{-n}\right)$

(7) $\gamma_{\mathrm{P}} \in \operatorname{median}_{\mathrm{n}}\left\{\Gamma_{\mathrm{n}}^{\mathrm{P}}\left(\gamma_{-\mathrm{n}}\right)\right\}$.

This notion of equilibrium is not the standard one. In particular, we are not looking at the Nash (or some refinement of the Nash) equilibrium of a well-specified game. Nevertheless, our formulation can be reinterpreted in strictly a game-theoretic mode. In fact, under the assumptions we make below, together with additional symmetry conditions, our equilibrium coincides with the unique equilibrium of two voting games after iterative elimination of weakly dominated strategies. In one voting game, each voter selects a type for the president and for the representative for the voter's district. The outcome of the election is given by the selected representatives for each district and the 
median, across districts, of the selected types for the president. In the other voting game, the president is elected by plurality voting across districts.

In our economy, there is a unique efficient allocation characterized by a level of government spending $g^{*}$, given by

$$
\mathrm{u}_{1}\left(\mathrm{~g}^{*}, \mathrm{y}-\mathrm{g}^{*}\right)=\mathrm{u}_{2}\left(\mathrm{~g}^{*}, \mathrm{y}-\mathrm{g}^{*}\right)
$$

To normalize, we assume that $\phi_{\mathrm{n}}(1, \ldots, 1 ; 1)=\mathrm{g}^{*}$. That is, if all representatives' types and the president's type are one, then the outcome is efficient.

We make the following assumptions.

Assumption 1 (Monotonicity): For all $\mathrm{n}$ and all $\mathrm{j}, \partial \phi_{\mathrm{n}} / \partial \gamma_{\mathrm{n}}>0, \partial \phi_{\mathrm{n}} / \partial \gamma_{\mathrm{P}}>0$

That is, if a local representative has higher lobbying ability, expenditures are greater in that district. Similarly, if the president's type is increased, spending increases in all districts.

Assumption 2 (Symmetry): The functions $\phi_{\mathrm{n}}$ are symmetric. That is, there is some function, $\phi$, such that $\phi_{n}\left(\gamma_{1}, \ldots, \gamma_{N} ; \gamma_{P}\right)=\phi\left(\gamma_{n}, \gamma_{-n} ; \gamma_{P}\right)$ and the ordering of the $\gamma_{-n}$ does not matter.

This is a standard symmetry condition. It states that the only factors that matter for local spending in district $\mathrm{n}$ are n's own representative, the types of other representatives, and the type of the president. In particular, local spending does not depend on $n$ itself or on the order of the types in the other districts.

Next, define the function $\alpha_{n}\left(\gamma, \gamma_{P}\right)$ by

$$
\alpha_{n}\left(\gamma, \gamma_{p}\right)=\frac{\frac{1}{N} \sum_{j} \frac{\partial \phi_{j}}{\partial \gamma_{n}}\left(\gamma, \ldots, \gamma ; \gamma_{P}\right)}{\frac{\partial \phi_{n}}{\partial \gamma_{n}}\left(\gamma, \ldots, \gamma ; \gamma_{P}\right)}
$$


The function $\alpha_{\mathrm{n}}$ is the ratio of marginal cost in terms of taxes to the marginal benefit in terms of government spending for the residents of district $n$ associated with increasing $\gamma_{n}$.

Assumption 3 (Budgetary Externality): $\alpha_{n}(1,1)<1$ for all $n$.

The content of Assumption 3, together with Assumption 1, is that an additional dollar of spending in a district is associated with less than a dollar increase in taxes paid by that district. In this sense, there is truly a budgetary externality.

Assumption 4 (Increasing Marginal Cost): The function $\alpha_{\mathrm{n}}$ is increasing in the representatives' types and decreasing in the president's type.

This is a standard concavity assumption. For example, this assumption says that the relative marginal cost of increasing government spending in all districts is increasing in the type of the local representative. The more fiscally liberal the congress is, the more costly it is to increase spending in any district, while the same conclusion holds if the president is more fiscally conservative.

Proposition 1: Assume that Assumptions 1-4 hold. In every symmetric equilibrium with, say, $\gamma_{\mathrm{n}}=$ $\gamma_{C}$ for all $n, \gamma_{P} \leq 1 \leq \gamma_{C}$, with at least one strict inequality. Furthermore, whenever $\gamma_{P}>\gamma_{\ell}$, the allocation is efficient. ${ }^{3}$

Proof: Suppose first that, for some n, the choice of president is interior. In this case, the following first-order condition must be satisfied:

$$
\left(\partial \phi_{\mathrm{n}} / \partial \gamma_{\mathrm{p}}\right) \mathrm{u}_{1}=(1 / \mathrm{N})\left(\sum_{\mathrm{k}} \partial \phi_{\mathrm{k}} / \partial \gamma_{\mathrm{P}}\right) \mathrm{u}_{2}
$$

Using Assumptions 1 and 2, we can rewrite (10) as

$$
\mathrm{u}_{1}=\mathrm{u}_{2} .
$$


From (11), it follows that the equilibrium level of spending is $\mathrm{g}^{*}$. Now Assumption 1 implies that either $\gamma_{P} \leq 1 \leq \gamma_{C}$, with at least one strict inequality, or $\gamma_{C} \leq 1 \leq \gamma_{P}$. Suppose that $\gamma_{C} \leq 1 \leq \gamma_{P}$. In this case, the first-order condition for the choice of representative is

$$
\left(\partial \phi_{\mathrm{n}} / \partial \gamma_{\mathrm{n}}\right) \mathrm{u}_{1} \leq(1 / \mathrm{N})\left(\sum_{\mathrm{k}} \partial \phi_{\mathrm{k}} / \partial \gamma_{\mathrm{n}}\right) \mathrm{u}_{2}=\alpha_{\mathrm{n}}\left(\partial \phi_{\mathrm{n}} / \partial \gamma_{\mathrm{n}}\right) \mathrm{u}_{2}
$$

From (11) and (12), it follows that $\alpha_{\mathrm{n}} \geq 1$. Since $\gamma_{\mathrm{C}} \leq 1 \leq \gamma_{\mathrm{P}}$, it follows from Assumptions 2 and 3 that $\alpha_{\mathrm{n}}<1$. This gives a contradiction.

Now consider the case in which $\gamma_{\mathrm{P}}=\gamma_{\mathrm{h}}$. In this case, the first-order condition for $\gamma_{\mathrm{P}}$ is $\mathrm{u}_{1} \geq$ $\mathrm{u}_{2}$. Under the assumption that the goods are both normal, this implies that the equilibrium level of spending is less than or equal to $\mathrm{g}^{*}$. Assumption 1 then implies that $\gamma_{\mathrm{C}}<1$. Using Assumption 3 , we have that $\alpha_{n}\left(\gamma_{C}, \gamma_{P}\right)<1$. However, the first-order condition for $\gamma_{C}$ and the fact that $u_{1} \geq u_{2}$ imply that $\alpha_{\mathrm{n}}\left(\gamma_{\mathrm{C}}, \gamma_{\mathrm{P}}\right) \geq 1$.

Finally, consider the case in which $\gamma_{\mathrm{P}}=\gamma_{\ell}$. In this case, the first-order condition for $\gamma_{\mathrm{P}}$ is $\mathrm{u}_{1}$ $\leq \mathrm{u}_{2}$. When the assumption that both goods are normal is used, the equilibrium level of spending is greater than or equal to $\mathrm{g}^{*}$. Assumption 1 implies that $\gamma_{\mathrm{C}}>1$. This completes the proof.

Proposition 1 formalizes the widely held view that voters elect fiscally liberal representatives to exploit the budgetary externality and a fiscally conservative president to restrain representatives from other districts. This proposition shows that this view has very strong implications. In particular, it shows that either public goods are allocated efficiently or the president's type is at its extreme.

The main conclusion of Proposition 1 is that there is a systematic difference in voting behavior in elections for local representatives and those for the president. This conclusion is, of course, Observation 1 in the introduction. We reach this conclusion because local representatives play a dual role in our model. They play a partial role in the determination of overall spending. And representatives act as advocates to guarantee that their districts are not short-changed in the budgetary 
process (i.e., $\partial \phi_{n} / \partial \gamma_{n}>0$ ). It is because of their role as advocates that voters are led to choose $\gamma_{n}>$ 1, even though this choice works against efficiency. As can be seen from Proposition 1, however, this choice causes an offsetting effect in the choice of the president, $\gamma_{P}<1$, which results in splitticket voting.

Moreover, we can see that each voter prefers that the makeup of the congress be changed. In particular, residents of district $n$ will receive higher utility if $\gamma_{i}=\gamma_{\ell}$ for $i \neq n$ (for all the other districts) than they do under the equilibrium outcome. This is Observation 2 in the introduction. Of course, Observation 3 follows directly from self-interested, maximizing behavior.

The result of Proposition 1, that the equilibrium is efficient when it is interior, relies on voters using their choices in a strategic way to obtain an appropriate balance between the congress and the president. Several factors might prevent this balance from being obtained in practice. We discuss two of these factors here. One is that it is natural to assume that the number of representatives is large. As it turns out, when $\mathrm{N}$ is large, there is a natural sense in which the case where $\gamma_{\mathrm{P}}=\gamma_{\ell}$ is the usual one. In particular, when the number of districts, $\mathrm{N}$, is large, the free rider problem associated with the budgetary externality drives overspending to an extreme. This is a standard effect of externality problems. Formally, $\gamma_{C} \rightarrow \infty$. Because of this effect, the type of the president is driven to the extreme. Here, if the president is not powerful enough to impose efficiency unilaterally, spending is at a higher-than-efficient level. This is the content of Proposition 2 below.

The other factor is that, even if the president has enough power to unilaterally enforce efficiency independent of the types in the congress, voters may choose to elect a type of president who will not enforce efficiency if it requires compromising voters' wishes on other nonbudgetary, global policy issues. Again, the intuition is the same: if $\mathrm{N}$ is large, voters must rely on extreme types for the president to restrain spending. If choosing a president this extreme requires compromise on social issues (such as abortion, judicial nominations, or foreign policy), voters may be forced to 
compromise on both fronts (even when all types are interior). Here, the issue is a bundling problem. The voters are forced into a choice: either choose a candidate for president who is more conservative than voters are on both fiscal and social matters (to undo the incentives to overspend in the congress) or choose a candidate for president who agrees with voters on social issues and allow overspending. Of course, in general, both of these margins will be compromised. This is the content of Proposition 3 below. $^{4}$

We begin by analyzing the situation in which the number of districts is large and, for simplicity, assume that the set of types possible is unbounded above. That is, $\gamma_{\mathrm{P}}, \gamma_{\mathrm{n}} \in\left[\gamma_{0}, \infty\right)$. Consider a sequence of systems indexed by $\mathrm{N}$, the number of districts, and assume that $\mathrm{u}_{1}$ is bounded below and that $\mathrm{u}_{2}(\mathrm{x}, 0)=\infty$.

Assumption 5 (Small Effects on Aggregates): For all $\mathrm{N}$ and $\mathrm{n}, \sum_{\mathrm{j}}\left(\partial \phi_{\mathrm{j}}^{\mathrm{N}} / \partial \gamma_{\mathrm{n}}\right) / \mathrm{N} \rightarrow 0$ uniformly in the types of the representatives.

This assumption says that when the number of districts is large, the effect on the average level of spending does not depend on the type of any individual representative. This assumption will hold if, for example, average spending depends only on the distribution of representatives' types.

Assumption 6 (Constant Effects on Local Spending): For all $N$ and n, $\partial \phi_{n}^{\mathrm{N}} / \partial \gamma_{\mathrm{n}}>0$ uniformly in $\mathrm{N}$ for any fixed level of $\gamma_{\mathrm{n}}$.

Assumption 6 says that, even given Assumption 5, the effect of a given representative on spending in his or her own district is bounded (uniformly) away from zero for fixed $\gamma_{\mathrm{n}}$. However, for fixed $\mathrm{N}$ and types of the other representatives, the effect on spending of the given representative necessarily goes to zero.

Taken together, Assumptions 5 and 6 say that the effect of a representative is of the first order at the local level, but is vanishing at the aggregate level. 
Assumption 7 (Limited Power of the President): For all $N$ and $n, \phi_{n}^{N}\left(\gamma, \ldots, \gamma ; \gamma_{\ell}\right)>g^{*}$ for large $\gamma$.

Assumption 7 says that the president has only limited ability in controlling the budgetary process. In particular, if the types of the representatives are extreme enough, there is no type for the president that can guarantee, by itself, that the level of spending will be efficient.

Under Assumption 7, it follows that, although the split-ticket voting result still holds, it is of an extreme nature, $\gamma_{\mathrm{P}}=\gamma_{\ell}$, when $\mathrm{N}$ is sufficiently large and $\gamma_{\mathrm{C}} \rightarrow \infty$. This follows from the analog of (10) and (12) when we use Assumptions 5-7. In this case, spending will be inefficiently high. We summarize this discussion in a proposition:

Proposition 2: In addition to Assumptions 1-4, assume that Assumptions 5-7 hold. When $\mathrm{N}$ is large, $\gamma_{P}=\gamma_{\ell}$ in every symmetric equilibrium and $\gamma_{C} \rightarrow \infty$. The equilibrium level of spending is above the efficient level, $\phi_{\mathrm{n}}^{\mathrm{N}}\left(\gamma_{\mathrm{C}} ; \gamma_{\mathrm{P}}\right)>\mathrm{g}^{*}$.

It is worth emphasizing that Proposition 2 is independent of the level of heterogeneity of preferences within a district. (In fact, the result does not rely on any limits to the extent of heterogeneity within each district as long as Assumptions 5-7 hold.) The fundamental conflict here is not among the voters of a given district as is common in voting models. Rather, it is among voters of different districts on the selection of their own representatives. Indeed, it is this conflict that leads voters (essentially regardless of their own preferences) to agree unanimously on the types of both their own representatives and the president — the most extreme types. We can show that Assumption 5 is actually stronger than is necessary. Indeed, what is important is that the equilibrium marginal cost of increased spending in a district is less than its benefit. (See the development in Section II below for a formulation without Assumption 5.)

We turn now to the second limit on efficiency in these types of models. Here, we show that our results on the types of representatives are robust to the inclusion of global issues, such as foreign 
policy or abortion, that may be of concern to voters. Under the reasonable assumption that representatives have a small effect on such global issues, we show that voters have an incentive to elect representatives who are best at bringing home "a piece of the pie," even if such representatives take positions on global issues that are contrary to the voters' interests. Thus, the characterization of the equilibrium choice of representative types given above when $\mathrm{N}$ is large is unaltered. In contrast, the result concerning the type of the president is not robust to the inclusion of these other issues.

Consider the following extension of our local public goods formulation. Each voter has preferences over private consumption $\mathrm{c}_{\mathrm{n}}$, government production in his or her district $\mathrm{g}_{\mathrm{n}}$, and a global issue denoted by $\zeta$, which for concreteness, we take to be foreign policy. These preferences are given by

$$
\mathrm{U}\left(\mathrm{g}_{\mathrm{n}}, \mathrm{c}_{\mathrm{n}}, \zeta\right)
$$

For simplicity, we assume that $\mathrm{U}$ is additively separable:

$$
\mathrm{U}\left(\mathrm{g}_{\mathrm{n}}, \mathrm{c}_{\mathrm{n}}, \zeta\right)=\mathrm{u}\left(\mathrm{g}_{\mathrm{n}}, \mathrm{c}_{\mathrm{n}}\right)+\mathrm{v}(\zeta)
$$

where $\mathrm{u}$ satisfies the assumptions given above and $\mathrm{v}$ is strictly concave.

As before, government spending is financed by uniform taxes. We continue to assume that the types of representatives and the president are one-dimensional measures of some attribute and denote this type by $\gamma$. Let $\phi_{\mathrm{n}}\left(\gamma_{1}, \gamma_{2}, \ldots, \gamma_{\mathrm{N}} ; \gamma_{\mathrm{P}}\right)$ and $\zeta\left(\gamma_{1}, \gamma_{2}, \ldots, \gamma_{\mathrm{N}} ; \gamma_{\mathrm{P}}\right)$ denote the spending outcome in district $\mathrm{n}$ and foreign policy, respectively.

Given the assumption of uniform taxation, it follows that the utility of the voters is given by

$$
\mathrm{u}\left(\phi_{\mathrm{n}}\left(\gamma_{1}, \gamma_{2}, \ldots, \gamma_{\mathrm{N}} ; \gamma_{\mathrm{P}}\right), \mathrm{y}-\sum_{\mathrm{k}} \phi_{\mathrm{k}}\left(\gamma_{1}, \gamma_{2}, \ldots, \gamma_{\mathrm{N}} ; \gamma_{\mathrm{P}}\right) / \mathrm{N}\right)+\mathrm{v}\left(\zeta\left(\gamma_{1}, \gamma_{2}, \ldots, \gamma_{\mathrm{N}} ; \gamma_{\mathrm{P}}\right)\right)
$$

Parallel to the analysis above, it is natural to make some normalizing assumptions. 
Assumption 8 (Monotonicity in Foreign Policy): $\partial \zeta / \partial \gamma_{P}>0$

Assumption 8 says that increasing the type of the president increases the level of foreign policy. Given our interpretation that higher $\gamma$ 's correspond to more liberal fiscal policies, we find it natural to interpret higher $\zeta$ 's as corresponding to more liberal policies on this front as well.

Because we want to isolate the effect of the budgetary externality, we assume that foreign policy does not, in and of itself, induce any biases into the system. Formally, let $\zeta^{*}=\zeta(1,1, \ldots, 1 ; 1)$, and assume that $\zeta^{*}$ is optimal, $\mathrm{v}^{\prime}\left(\zeta^{*}\right)=0$. That is, given our previous assumptions relating to the $\phi$ 's, choosing all elected officials of type $\gamma=1$ gives rise to the efficient outcome for both fiscal and foreign policy issues.

The characterization of the equilibrium is parallel to that given above. The first-order conditions for an interior solution with respect to a representative's type is

$$
\mathrm{u}_{1} \partial \phi_{\mathrm{n}} / \partial \gamma_{\mathrm{n}}+\mathrm{v}^{\prime} \partial \zeta / \partial \gamma_{\mathrm{n}}=\mathrm{u}_{2} \sum_{\mathrm{k}}\left(\partial \phi_{\mathrm{k}} / \partial \gamma_{\mathrm{n}}\right) / \mathrm{N}
$$

We assume that when the legislature is large, the effect of any single representative on foreign policy is small. To simplify the analysis, we adopt the extreme assumption that this effect is zero. Thus, consider a sequence of environments where $\zeta$ 's and $\phi$ 's are indexed by the number of districts, N. We make the following assumptions.

Assumption 9 (Small Effects of Representatives): $\partial \zeta^{\mathrm{N}} / \partial \gamma_{\mathrm{n}}=0$ for all N.

Assumption 10 (Bounded Role of Global Policy): v' is uniformly bounded above and below.

It follows that when $\mathrm{N}$ is large, $\gamma_{\mathrm{C}} \rightarrow \infty$ as in Proposition 2. Thus, regardless of how important the global issue is to the voter (that is, how large $u_{3}$ is) and regardless of the consequences for foreign policy (that is, the sign of $\mathrm{v}^{\prime}$ is irrelevant), voters find it in their interest to maximize spending in their own districts. 
In contrast, consider the first-order condition with respect to the choice of the president's type. If the solution is interior, this condition is

$$
\mathrm{u}_{2}(1 / \mathrm{N}) \sum \partial \phi_{\mathrm{k}} / \partial \gamma_{\mathrm{P}}=\mathrm{u}_{1} \partial \phi_{\mathrm{n}} / \partial \gamma_{\mathrm{P}}+\mathrm{v}^{\prime} \partial \zeta / \partial \gamma_{\mathrm{P}}
$$

Under symmetry, equation (16) can be written as

$$
\left(\mathrm{u}_{2}-\mathrm{u}_{1}\right) \partial \phi_{\mathrm{n}} / \partial \gamma_{\mathrm{P}}=\mathrm{v}^{\prime} \partial \zeta / \partial \gamma_{\mathrm{P}}
$$

It follows from (17) that our conclusion from Proposition 2, $\gamma_{\mathrm{P}}=\gamma_{\ell}$, need not hold in this more general setting. In this sense, including nonbudgetary issues into government decision making may affect the president's type, but does not affect the types of representatives. Moreover, because under our assumptions, optimality of foreign policy requires that $\gamma_{\mathrm{P}}=1$ (because this is where $\mathrm{v}^{\prime}=$ 0 ), it follows from (17) that $\mathrm{u}_{1}<\mathrm{u}_{2}$ and $\mathrm{v}^{\prime}>0$ in equilibrium. [Increasing $\gamma_{\mathrm{P}}$ from one makes $\mathrm{v}^{\prime}<$ 0 and $\mathrm{u}_{2}>\mathrm{u}_{1}$, violating (17).] It follows that, in equilibrium, spending is higher than its optimal level, while foreign policy is too conservative. This reflects the natural compromise on the part of voters. In order to counteract the fiscal liberalism in the congress, voters have a tendency to elect a president who is overly fiscally conservative. Because this also moves foreign policy too far to the conservative side, voters compromise and choose a level of spending that is too liberal and foreign policy that is too conservative. We summarize this discussion in the following proposition.

Proposition 3: Under Assumptions 8-10, when $\mathrm{N}$ is large, $\gamma_{C} \rightarrow \infty$ and the type of the president is distorted relative to efficiency on both the spending and global policy issues in all interior equilibria. As a result, spending is higher than optimal and global policy is too conservative.

Here, we have implicitly linked the types of the president on the two issues by assuming that the type space is one-dimensional. In more general formulations, it is possible to get the efficiency result if a candidate exists who is more fiscally conservative than the population as a whole and, at 
the same time, has the right preferences over the global issue. Note that this possibility requires a candidate with preferences distinct from those of the voters (and, hence, such candidates may not be present in the population).

The theory can be used to help understand the increase throughout the twentieth century in aggregate government spending and the accompanying increase in split-ticket voting. (See Zupan 1991 for documentation of increased split-ticket voting.) Consider the comparative statics exercise where $\alpha_{n}$ falls. (Recall that $\alpha_{n}$ is the ratio of marginal cost to marginal benefit for the residents of district $\mathrm{n}$ associated with increasing $\gamma_{\mathrm{n}}$.) One interpretation of a decline in $\alpha_{\mathrm{n}}$ is that decision making in the congress becomes more "democratized." In the model, this results in a worsening of the free rider problem. If the president's type is $\gamma_{\ell}$, (i.e., $\mathrm{N}$ is large), it follows that, in equilibrium, the type elected to the congress, $\gamma_{\mathrm{C}}$, rises as does aggregate spending. (See Christopher Deering and Steven Smith 1990 for evidence that decision making in Congress has become steadily democratized over the twentieth century.)

Simple adaptations of this model can be used to study other constitutional arrangements, such as parliamentary systems. These adaptations will be discussed in detail in Section III below.

\section{A Detailed Model of Bargaining Between the President and the Congress}

A key finding of the preceding section is that, because there is split-ticket voting in equilibrium, it cannot be true that both the type of the representative and of the president reflect the individual voters' preferences over spending on public goods. That is, voters systematically choose representatives (and/or a president) whose preferences are different from their own. In this section, we explore this issue further. We consider a simple model of bargaining over the budget based on the work of Baron and Ferejohn (1989). (See also Baron 1993.) We use a parameterized version of voters' preferences for spending and show that in equilibrium, voters pick representatives who have 
a greater preference for spending than the voters do themselves. Thus, this version gives us one simple interpretation of the lobbying ability discussed in Section I. Here, voters strategically delegate their decision-making power to representatives who differ from themselves so as to increase the probability that the representatives will be included in a winning coalition. To form a majority coalition, the proposer of the budget will choose those representatives to whom the proposer has to promise the least (in terms of the provision of local public goods). This setting results in a Bertrandstyle competition among the voters for the types of the representatives, driving the representatives to extremes when $\mathrm{N}$ is large. Contrast this setting with one in which the voters know their representative will be the budget proposer. In this case, the voters will elect a representative whose type agrees with their own.

Thus, we accomplish two tasks with this model. It provides microfoundations for the model in the previous section. And it shows that the bargaining process within Congress can affect the type of representative to whom voters delegate authority.

The utility function for voters in district $\mathrm{n}$ is assumed to be of the form

$$
\mathrm{U}=\mathrm{f}\left(\mathrm{g}_{\mathrm{n}}\right)-\mathrm{T}_{\mathrm{n}}
$$

where $\mathrm{g}$ denotes spending in the district and $\mathrm{T}$ denotes taxes paid by voters in the district. We assume that $f(\bullet)$ is strictly increasing and concave, $f^{\prime}(0)=\infty$, and $f(0)=0$.

We assume that each district has a local government that can provide local spending, and, for simplicity, we assume that the local government acts in a benevolent manner, maximizing the utility of the local residents given the behavior of the central government. Specifically, the federal government specifies a level of federal expenditures for each district, $g_{n}, n=1, \ldots, N$, financed by uniform lump-sum taxes on voters in all districts. Local governments can supplement these 
expenditures, but they cannot reduce the level of expenditures in their districts. Let $g^{*}$ denote the efficient level of expenditures in a district. That is, $\mathrm{g}^{*}$ solves

$$
\mathrm{f}^{\prime}\left(\mathrm{g}^{*}\right)=1
$$

Note that $\mathrm{g}^{*}$ is the same in all districts, because the function $\mathrm{f}$ is assumed to be the same for each voter. Further, this specification of utility abstracts from any income effects. It follows that if the level of federal spending in district $\mathrm{n}, \mathrm{g}_{\mathrm{n}}$, is larger than $\mathrm{g}^{*}$, the local government does not provide any additional spending. However, if $g_{\mathrm{n}}<\mathrm{g}^{*}$, the local government supplements the level of spending up to the efficient level $\mathrm{g}^{*}$. It follows that the derived utility of voters in district $\mathrm{n}$, given a level of spending in each district and a level of federal taxes, is given by

$$
\mathrm{U}=\mathrm{f}\left(\mathrm{g}_{\mathrm{n}}+\max \left[\mathrm{g}^{*}-\mathrm{g}_{\mathrm{n}}, 0\right]\right)-\left\{\tau / \mathrm{N}+\max \left[\mathrm{g}^{*}-\mathrm{g}_{\mathrm{n}}, 0\right]\right\}
$$

Representatives have utility functions given by

$$
\mathrm{U}_{\mathrm{n}}\left(\mathrm{g}_{1}, \ldots, \mathrm{g}_{\mathrm{N}}, \tau ; \gamma_{\mathrm{n}}\right)=\gamma_{\mathrm{n}} \mathrm{f}\left(\mathrm{g}_{\mathrm{n}}+\max \left[\mathrm{g}^{*}-\mathrm{g}_{\mathrm{n}}, 0\right]\right)-\left\{\tau / \mathrm{N}+\max \left[\mathrm{g}^{*}-\mathrm{g}_{\mathrm{n}}, 0\right]\right\}
$$

with $\gamma_{\mathrm{n}} \in\left[\gamma_{\ell}, \gamma_{\mathrm{h}}\right]$ and $\gamma_{\ell}<1<\gamma_{\mathrm{h}}$.

The president views all districts equally and has a utility function given by

$$
\mathrm{U}_{\mathrm{P}}\left(\mathrm{g}_{1}, \ldots, \mathrm{g}_{\mathrm{N}}, \tau ; \gamma_{\mathrm{P}}\right)=\gamma_{\mathrm{P}} \sum \mathrm{f}\left(\mathrm{g}_{\mathrm{n}}+\max \left[\mathrm{g}^{*}-\mathrm{g}_{\mathrm{n}}, 0\right]\right)-\left\{\tau+\sum \max \left[\mathrm{g}^{*}-\mathrm{g}_{\mathrm{n}}, 0\right]\right\}
$$

where $\gamma_{P}$ represents the type of the president. We assume that $\gamma_{P} \in\left[\gamma_{\ell}, \gamma_{h}\right]$. A balanced budget requires that

$$
\tau=\sum_{\mathrm{n}} \mathrm{g}_{\mathrm{n}}
$$

We assume that after representatives and the president are elected, a coin is flipped to determine whether the proposer of a budget will be the president or the congress. Let $\pi$ denote the probability that the congress is selected. If the congress is selected, one of the elected representatives is chosen at random with equal probabilities to propose a budget. A budget proposal by either the 
selected representative or the president consists of a list of federal spending levels for the $\mathrm{N}$ districts, $\left(\mathrm{g}_{1}, \ldots, \mathrm{g}_{\mathrm{N}}\right)$. After a budget is proposed, the congress votes sequentially on whether or not the budget bill will be enacted. Enactment occurs if there are at least $(\mathrm{N}+1) / 2$ yes votes, where we assume that $\mathrm{N}$ is odd for simplicity.

If the bill is enacted, spending is distributed according to the proposed plan and utility levels are realized. If the bill is not enacted, federal spending in each district is given by a status quo level $\mathrm{g}^{* *}$ in all districts, where we assume that $\mathrm{g}^{* *} \leq \mathrm{g}^{*}$. We discuss relaxing this assumption following the proof of the next proposition.

We show that, given that all the other representatives have types $\gamma_{h}$, each voter's most preferred choice for president is any $\gamma_{\mathrm{P}} \leq 1$, and each voter's most preferred choice for representative is $\gamma_{\mathrm{n}}=\gamma_{\mathrm{h}}$. Thus, in equilibrium, $\gamma_{\mathrm{P}} \leq 1$ and $\gamma_{\mathrm{n}}=\gamma_{\mathrm{h}}$ for all $\mathrm{n}$.

Proposition 4: Suppose that $\gamma_{\mathrm{h}}<(\mathrm{N}-1) / 2, \mathrm{~g}^{* *} \leq \mathrm{g}^{*}$, and the utility function $\mathrm{f}$ satisfies af $(\mathrm{ax}) \geq \mathrm{f}^{\prime}(\mathrm{x})$ for all $\mathrm{x}$ and all $\mathrm{a}>1$. Then the vector of types given by $\left(\gamma_{h}, \gamma_{h}, \ldots, \gamma_{h} ; \gamma_{P}\right)$, where $\gamma_{P} \leq 1$, is an equilibrium.

Proof: We construct an equilibrium of the bargaining game between the president and the congress that has the following properties. Given that $\gamma_{2}=\gamma_{3}=\ldots=\gamma_{N}=\gamma_{h}$, the most preferred types for voter 1 are $\gamma_{1}=\gamma_{\mathrm{h}}$ and $\gamma_{\mathrm{P}} \leq 1$. In the equilibrium of the bargaining game, the allocation to district 1 is independent of the representative's type if the president is chosen to propose, while the allocation is independent of the president's type if the congress is chosen to propose. It follows that, in this equilibrium, the most preferred choice for president can be found by examining only the branch of the game tree in which the president proposes, and the most preferred choice for representative can be found by examining only the branch in which the congress proposes.

Consider voter 1's choice for president. If the president is chosen as the proposer, every equilibrium outcome of the bargaining game can be found as a solution to the following problem: 
$\max \mathrm{U}_{\mathrm{P}}\left(\mathrm{g}_{1}, \ldots, \mathrm{g}_{\mathrm{N}}, \Sigma \mathrm{g}_{\mathrm{n}} ; \gamma_{\mathrm{P}}\right)$

subject to

(a) $\quad \delta_{\mathrm{i}}\left\{\mathrm{U}_{\mathrm{i}}\left(\mathrm{g}_{1}, \ldots, \mathrm{g}_{\mathrm{N}}, \Sigma \mathrm{g}_{\mathrm{n}} / \mathrm{N} ; \gamma_{\mathrm{i}}\right)-\mathrm{U}_{\mathrm{i}}\left(\mathrm{g}^{* *}, \ldots, \mathrm{g}^{* *}, \mathrm{~g}^{* *} ; \gamma_{\mathrm{i}}\right)\right\} \geq 0$

(b) $\quad \delta_{\mathrm{i}} \in\{0,1\}$

(c) $\quad \Sigma \delta_{i} \geq(\mathrm{N}+1) / 2$

where $\mathrm{U}_{\mathrm{P}}(\bullet)$ is given by $(22)$ and $\mathrm{U}_{\mathrm{i}}(\bullet)$ is given by $(21)$.

The interpretation of the $\delta$ 's in this problem is that $\delta_{i}=1$ if the representative from district $\mathrm{i}$ votes for the proposal, while $\delta_{i}=0$ means that the representative from district $\mathrm{i}$ votes against the proposal. Given this interpretation, constraint (24)(a) requires that each representative who is voting for the proposal is at least as well off if the proposal passes as if it fails. Constraint (24)(c) requires that a majority of the representatives vote for the proposal.

Consider the most preferred proposal of the president. This can be found by choosing spending levels to maximize the utility of the president subject to (23). Suppose first that $\gamma_{P} \leq 1$. Then the president's most preferred proposal is given by $g_{i}\left(\gamma_{P}\right)=g^{*}$ for all i. Suppose that $\gamma_{p}>1$. Then $\mathrm{g}_{\mathrm{i}}\left(\gamma_{\mathrm{P}}\right)$ is given by

$$
\gamma_{\mathrm{P}} \mathrm{f}^{\prime}\left(\mathrm{g}_{\mathrm{i}}\left(\gamma_{\mathrm{P}}\right)\right)=1
$$

Consider now constraint (24)(a) for representatives from districts 2,,..,N. We claim that this constraint is satisfied at the proposed level of spending. To see this, note that if the president's proposal fails, spending levels in the districts are given by $\mathrm{g}^{*}$. If the president's proposal passes, spending levels are given by $\mathrm{g}_{\mathrm{i}}\left(\gamma_{\mathrm{P}}\right)$. But

$$
\gamma_{h}\left(f\left(g_{i}\left(\gamma_{P}\right)\right)-f\left(g^{*}\right)\right)-\left(g_{i}\left(\gamma_{P}\right)-g^{*}\right) \geq \gamma_{P}\left(f\left(g_{i}\left(\gamma_{P}\right)\right)-f\left(g^{*}\right)\right)-\left(g_{i}\left(\gamma_{P}\right)-g^{*}\right) \geq 0
$$


where the first inequality follows because $\gamma_{P} \leq \gamma_{h}$ and $g_{i}\left(\gamma_{P}\right) \geq g^{*}$, and the second inequality follows because $\mathrm{g}_{\mathrm{i}}\left(\gamma_{\mathrm{P}}\right)$ maximizes the president's utility. It follows that the president can implement his or her preferred proposal regardless of the type of the representative from district 1 . Hence, the voters in district 1 care only about the type of the president along this branch of the tree. The voters' utility is given by

$$
\mathrm{U}_{1}\left(\gamma_{\mathrm{P}}\right)=\mathrm{f}\left(\mathrm{g}_{1}\left(\gamma_{\mathrm{P}}\right)\right)-\mathrm{g}_{1}\left(\gamma_{\mathrm{P}}\right)
$$

Thus, utility is maximized by $\gamma_{\mathrm{P}} \leq 1$.

Given that the president's type affects neither spending nor taxes on the branch in which the congress proposes, it follows that the voters' most preferred type for president is any $\gamma_{\mathrm{P}} \leq 1$ along this branch as well.

Consider now the branch of the tree where the congress moves first, and suppose that representative $\mathrm{i}$ is selected as the proposer. This representative solves the following problem:

$$
\max \mathrm{U}_{\mathrm{i}}\left(\mathrm{g}_{1}, \ldots, \mathrm{g}_{\mathrm{N}}, \Sigma \mathrm{g}_{\mathrm{n}} / \mathrm{N} ; \gamma_{\mathrm{i}}\right)
$$

subject to

$$
\begin{aligned}
& \text { (a) } \delta_{j}\left(U_{j}\left(g_{1}, \ldots, g_{N}, \Sigma g_{n} / N ; \gamma_{j}\right)-U_{i}\left(g^{* *}, \ldots, g^{* *}, g^{* *} ; \gamma_{j}\right)\right) \geq 0, j \neq i \\
& \text { (b) } \delta_{j} \in\{0,1\} \\
& \text { (c) } \sum_{j \neq i} \delta_{j} \geq(N-1) / 2 .
\end{aligned}
$$

Now consider the case in which representative 1 is not the proposer. We show that if $\gamma_{1}<$ $\gamma_{\mathrm{h}}$, the solution to this problem has $\delta_{1}=0$ (i.e., representative 1 is not in the winning coalition) and $\mathrm{g}_{1}=0$. To see this, we compute the utility level of the proposer assuming representative 1 is not included. Inspection of problem (27) shows that the proposer's utility is maximized by setting federal spending equal to zero for all except $(\mathrm{N}+1) / 2$ districts, setting spending in $(\mathrm{N}-1) / 2$ districts equal to the smallest feasible level consistent with (27)(a), and setting spending in the proposer's district at 
the highest level so that (27)(a) holds with equality. Specifically, let G denote federal spending in those districts that are part of the winning coalition, and let $\mathrm{g}$ denote spending in the proposer's district. Then, the proposer's problem is

$$
\max \gamma_{\mathrm{h}} \mathrm{f}(\mathrm{g})-[\mathrm{g} / \mathrm{N}+\mathrm{G}(\mathrm{N}-1) / 2 \mathrm{~N}]
$$

subject to

(a) $\quad \gamma_{\mathrm{h}} \max \left[\mathrm{f}(\mathrm{G}), \mathrm{f}\left(\mathrm{g}^{*}\right)\right]-[\mathrm{g} / \mathrm{N}+\mathrm{G}(\mathrm{N}-1) / 2 \mathrm{~N}]-\max \left[\mathrm{g}^{*}-\mathrm{G}, 0\right] \geq$

$$
\gamma_{h} f\left(g^{*}\right)-g^{*} \text {. }
$$

We show that $G>g^{*}$. To see this, suppose that $G=g^{*}$. We show that increasing $G$ allows the proposer to increase spending in the proposer's own district, g, and to increase the proposer's own utility. From (28)(a), we have that

$$
\left.\frac{\mathrm{dG}}{\mathrm{dg}}\right|_{\mathrm{G}=\mathrm{g}^{*}}=\frac{1}{\mathrm{~N}\left(\gamma_{\mathrm{h}} \mathrm{f}^{\prime}\left(\mathrm{g}^{*}\right)-\frac{\mathrm{N}-1}{2 \mathrm{~N}}\right)} .
$$

Substituting for (29) in the objective function (28), we get

$$
\frac{d U}{d g}=\gamma_{h} f^{\prime}(g)-\frac{1}{N}-\frac{N-1}{2 N}\left(\frac{1}{N\left(\gamma_{h} f^{\prime}\left(g^{*}\right)-\frac{N-1}{2 N}\right)}\right)
$$

Now, at $\mathrm{G}=\mathrm{g}^{*}$, we have that spending in the proposer's district is $\mathrm{g}=\mathrm{Ng}^{*}(1-(\mathrm{N}-1) / 2 \mathrm{~N})$.

Because $\gamma_{\mathrm{h}}>1$ and $\mathrm{f}^{\prime}\left(\mathrm{g}^{*}\right)=1$, we have that

$$
\frac{d U}{d g}>\gamma_{h} f^{\prime}\left(\frac{N^{*}(N+1)}{2 N}\right)-\frac{1}{N}-\frac{N-1}{2 N^{2}}\left(\frac{1}{1-\frac{N-1}{2 N}}\right)
$$

Or rearranging (31), we get 


$$
\frac{d U}{d g}>\gamma_{h} f^{\prime}\left(\frac{N g^{*}(N+1)}{2 N}\right)-\frac{1}{N}-\frac{N-1}{N(N+1)}=\gamma_{h} f^{\prime}\left(\frac{N g^{*}(N+1)}{2 N}\right)-\frac{2}{N+1}
$$

From our assumptions about the benefit function, we have that $\gamma_{h} f^{\prime}\left(g^{*}(N+1) / 2\right)(N+1) / 2 \geq$ $\gamma_{\mathrm{h}} \mathrm{f}^{\prime}\left(\mathrm{g}^{*}\right)>1$. It follows that $\mathrm{dU} / \mathrm{dg}>0$. It is straightforward to use this argument to show that $\mathrm{G}>$ $\mathrm{g}^{*}$.

Next, we turn to the utility level of the proposer if the representative from district 1 (with type $\left.\gamma_{1}<\gamma_{\mathrm{h}}\right)$ is included in the winning coalition. Let $\mathrm{g}$ denote spending in the proposer's district, $\mathrm{g}_{1}$ in district 1 , and $\mathrm{G}$ in the remaining $(\mathrm{N}-2) / 2$ districts. Using the same argument as above, we can show that $\mathrm{g}_{1}>\mathrm{g}^{*}$. Because representative 1 votes for the proposal, it must be that

$$
\gamma_{1}\left(\mathrm{f}\left(\mathrm{g}_{1}\right)-\mathrm{f}\left(\mathrm{g}^{*}\right)\right)-\left(\mathrm{g} / \mathrm{N}+\mathrm{g}_{1} / \mathrm{N}+\mathrm{G}(\mathrm{N}-2) / 2 \mathrm{~N}-\mathrm{g}^{*}\right)=0
$$

But $\gamma_{h}\left(f\left(g_{1}\right)-f\left(g^{*}\right)\right)>\gamma_{1}\left(f\left(g_{1}\right)-f\left(g^{*}\right)\right)$. Therefore, if the proposer includes a representative from one of the other districts in place of representative 1, slack is introduced in (27)(a) and the proposer can be made strictly better off. It follows that if representative 1 is in the winning coalition, representative 1 's type must be $\gamma_{\mathrm{h}}$.

Consider now the case in which representative 1 is the proposer. The representative's problem is

$$
\max \gamma_{1} \mathrm{f}(\mathrm{g})-(\mathrm{g} / \mathrm{N}+\mathrm{G}(\mathrm{N}-1) / 2 \mathrm{~N})
$$

subject to

$$
\gamma_{\mathrm{h}} \mathrm{f}(\mathrm{G})-(\mathrm{g} / \mathrm{N}+\mathrm{G}(\mathrm{N}-1) / 2 \mathrm{~N}) \geq \gamma_{\mathrm{h}} \mathrm{f}\left(\mathrm{g}^{*}\right)-\mathrm{g}^{*}
$$

The first-order condition for this problem is

$$
(\mathrm{N}-1) / 2=\left(\gamma_{1} \mathrm{f}^{\prime}(\mathrm{g})-1 / \mathrm{N}\right)\left(\gamma_{\mathrm{h}} \mathrm{f}^{\prime}(\mathrm{G})-(\mathrm{N}-1) / 2 \mathrm{~N}\right)
$$


Let $\mathrm{g}\left(\gamma_{1}\right)$ denote the solution to this problem. Inspection of the first-order condition shows that $\mathrm{g}\left(\gamma_{1}\right)$ is increasing in $\gamma$.

We use these results to show that the expected utility of the voters in district 1 is maximized when $\gamma_{1}=\gamma_{\mathrm{h}}$. Consider the expected utility of the voter when the representative's type is $\gamma_{1}$. With probability $1 / \mathrm{N}$, the representative is the proposer and spending in district 1 is $\mathrm{g}$. With probability $(1-1 / \mathrm{N})$, the representative is not the proposer, and then with probability $(\mathrm{N}-1) / 2 \mathrm{~N}$, spending in district 1 is $\mathrm{G}$. The tax burden is $\mathrm{g} / \mathrm{N}+\mathrm{G}(\mathrm{N}-1) / 2 \mathrm{~N}$ independent of the proposer's identity. This gives the following expression for utility:

$$
\mathrm{U}\left(\gamma_{\mathrm{h}}\right)=\mathrm{f}(\mathrm{g}) / \mathrm{N}+(\mathrm{N}-1) \mathrm{f}(\mathrm{G}) / 2 \mathrm{~N}-(\mathrm{g} / \mathrm{N}+\mathrm{G}(\mathrm{N}-1) / 2 \mathrm{~N})
$$

If, instead, the representative's type is $\gamma<\gamma_{h}$, with probability $1 / \mathrm{N}$, spending in district 1 is $\mathrm{g}_{1}(\gamma)$ and the tax burden is $\mathrm{g}_{1}(\gamma) / \mathrm{N}+\mathrm{G}_{1}(\gamma)(\mathrm{N}-1) / 2 \mathrm{~N}$. With probability $(1-1 / \mathrm{N})$, representative 1 is not the proposer, spending in district 1 is zero, and the tax burden is $g / N+G(N-1) / 2 N$. The expected utility of the voter is

$$
\mathrm{U}(\gamma)=\mathrm{f}\left(\mathrm{g}_{1}(\gamma)\right) / \mathrm{N}-1 / \mathrm{N}\left(\mathrm{g}_{1}(\gamma) / \mathrm{N}+\mathrm{G}_{1}(\gamma)(\mathrm{N}-1) / 2 \mathrm{~N}\right)-(1-1 / \mathrm{N})(\mathrm{g} / \mathrm{N}+\mathrm{G}(\mathrm{N}-1) / 2 \mathrm{~N})
$$

Comparing (33) and (34) and using the fact that $\mathrm{g}_{1}(\gamma) \leq \mathrm{g}$, we have that $\mathrm{U}\left(\gamma_{\mathrm{h}}\right)>\mathrm{U}(\gamma)$ if

$$
(\mathrm{N}-1) \mathrm{f}(\mathrm{G}) / 2 \mathrm{~N} \geq 1 / \mathrm{N}(\mathrm{g} / \mathrm{N}+\mathrm{G}(-1) / 2 \mathrm{~N})
$$

Using (28)(a), we have that $\mathrm{U}\left(\gamma_{\mathrm{h}}\right)>\mathrm{U}(\gamma)$ if

$$
(N-1) f(G) / 2 N \geq \gamma_{h} f(G) / N-\left(\gamma_{h} f\left(g^{*}\right)-g^{*}\right)
$$

Because $\gamma_{\mathrm{h}} \leq(\mathrm{N}-1) / 2$, the last inequality follows immediately, which completes the proof.

Note that the condition $\mathrm{af}^{\prime}(\mathrm{ax})>\mathrm{f}^{\prime}(\mathrm{x})$ for all $\mathrm{x}$ and for all $\mathrm{a}>1$ is satisfied for all benefit functions of the form $f(x)=x^{\alpha} / \alpha$ for $0 \leq \alpha \leq 1$. 
The proof of this proposition shows that voters engage in strategic delegation to ensure that their representatives are included in the winning coalition. A different way of seeing this is to suppose that district 1's representative is the proposer with probability one. Then it is possible to show that the voters elect a representative whose type is identical to their own. That is, there is no strategic delegation. If the probability that the representative is the proposer is strictly less than one, voters have an incentive to elect a representative who likes spending just enough to be included in the winning coalition. Because voters in all districts have the same incentives, competition among the districts drives all representatives' types to the most tolerant level.

The nature of the equilibrium changes somewhat when the status quo spending level satisfies

$\mathrm{g}^{* *}>\mathrm{g}^{*}$. In this case, if all representatives other than representative 1 are of type $\gamma_{\mathrm{h}}$, the voters in district 1 have an incentive to pick an extremely conservative president and a representative whose type is slightly below $\gamma_{\mathrm{h}}$. The reason for this is that this type for the president seeks to minimize total spending. The president does so by attempting to reduce spending below $\mathrm{g}^{* *}$ for districts in the winning coalition and setting federal spending in all other districts to zero. We conjecture that splitticket voting is still an equilibrium in this case, but that the representatives' types are not driven to a corner. We do not pursue this avenue, since the results depend on a variety of details, such as the probability that the president chooses allocations, and on the exact shape of the benefit function, $f(\bullet)$.

\section{Extensions of the Basic Model}

In this section, we examine two extensions of the models in the sections above. In one, we use the analysis of Section I to compare the bias toward overspending in presidential and parliamentary systems. We show that, without other types of restrictions on the budgetary process, the parliamentary system fares worse. In the other extension, we use a dynamic extension of the analysis of Section II to examine the recent popularity of term limits for representatives. 
Example 1 (Parliamentary Systems): As we have seen in Section I, in a presidential system, the (directly elected) president may play the role of offsetting extremism (of either type) in the congress in the budgetary process. In particular, the split-ticket voting result presented there shows that the president's type is not represented in the congress. In contrast to this, in a parliamentary system, the president (or prime minister) is a member of the parliament and, therefore the president's type must be selected from among those in the parliament. We can use our basic model to study how these different constitutional arrangements affect public spending in the presence of a budgetary externality.

In order to study a parliamentary system, we introduce two additional assumptions. The first is a natural assumption on voting procedures for the election of the president from within the parliament. It is a no-veto assumption that is satisfied if, for example, the president is elected by majority voting.

Assumption 11 (No Veto): For each district $i$, if $\gamma_{j}=\gamma^{*}$ for all $j \neq i$, then the elected president's type, $\gamma_{\mathrm{P}}$, is $\gamma^{*}$.

This assumption guarantees that, in a symmetric equilibrium, when representatives are elected, voters do not have to take into account how the representative will vote in the parliament's election of the president. It also allows us to abstract from specific voting procedures within the parliament.

In a symmetric equilibrium with $\gamma_{i}=\gamma$ for all $i$, the parliamentary system can be viewed as a constitutional system that satisfies the constraint $\gamma_{P}=\gamma$. The following assumption limits the effect that, according to Assumption 4, the president's type can have on the marginal cost of public spending.

Assumption 12 (Nondecreasing Marginal Cost): $\alpha(\gamma, \gamma)$ is nondecreasing in $\gamma$. 
The next proposition confirms the intuition that, without the corrective influence of a fiscally conservative president, a parliamentary system will result in even higher levels of spending than a presidential system.

Proposition 5: In addition to Assumptions 1-4, assume that Assumptions 11 and 12 hold. Let $g_{\text {pres }}$ be the equilibrium level of local spending in a presidential system and $g_{\text {parl }}$ be the level in a parliamentary system. Then $\mathrm{g}_{\text {parl }}>\mathrm{g}_{\text {pres }} \geq \mathrm{g}^{*}$, the optimal level.

Proof: Let $\left(\gamma_{\mathrm{C}}, \gamma_{\mathrm{P}}\right)$ be the equilibrium distribution of types under the presidential system (symmetric in representative's types), and let $\left(\gamma^{*}, \gamma^{*}\right)$ be the (symmetric) distribution of types under the parliamentary system.

If $\gamma^{*}=\gamma_{\mathrm{h}}$, the result follows from the fact that $\gamma_{\mathrm{P}}<1$ (Proposition 1) and Assumption 1 . Therefore, in the remainder of the proof, we suppose that $\gamma^{*}<\gamma_{h}$. The first-order condition for the choice of the $\gamma^{*}$ is $u_{1} \leq \alpha u_{2}$.

Suppose that $\gamma^{*} \leq 1$. Then by Assumption 12, $\alpha\left(\gamma^{*}, \gamma^{*}\right) \leq \alpha(1,1)<1$. (The last inequality is from Assumption 3.) But then our normality assumption implies that $g_{\text {parl }}>g^{*}$. However, by Assumption 1, if $\gamma^{*} \leq 1, \mathrm{~g}_{\text {parl }}=\phi_{\mathrm{n}}\left(\gamma^{*}, \gamma^{*}\right) \leq \phi_{\mathrm{n}}(1,1)=\mathrm{g}^{*}$. This contradiction establishes that $\gamma^{*}>1$. From Assumption 1, then, it follows that $g_{\text {parl }}>g^{*}$.

It follows directly that whenever the presidential system is efficient (i.e., when $\gamma_{P}=\gamma_{\ell}$ and $\left.\mathrm{g}_{\text {pres }}=\mathrm{g}^{*}\right), \mathrm{g}_{\text {parl }}>\mathrm{g}_{\text {pres }}=\mathrm{g}^{*}$.

Now consider the case in which $\gamma_{\mathrm{P}}=\gamma_{\ell}$, and suppose that $\mathrm{g}_{\mathrm{parl}} \leq \mathrm{g}_{\mathrm{pres}}$. By normality, it follows that

$$
\frac{\mathrm{u}_{1}\left(\mathrm{~g}_{\text {pres }} \mathrm{y}-\mathrm{g}_{\text {pres }}\right)}{\mathrm{u}_{2}\left(\mathrm{~g}_{\text {pres }} \mathrm{y}-\mathrm{g}_{\text {pres }}\right)} \leq \frac{\mathrm{u}_{1}\left(\mathrm{~g}_{\text {parl }} \mathrm{y}-\mathrm{g}_{\text {parl }}\right)}{\mathrm{u}_{2}\left(\mathrm{~g}_{\text {parl }} \mathrm{y}-\mathrm{g}_{\text {parl }}\right)}
$$


which implies that $\alpha\left(\gamma^{*}, \gamma^{*}\right) \geq \alpha\left(\gamma_{C}, \gamma_{\mathrm{P}}\right)$. However, if $\gamma^{*}<\gamma_{\mathrm{C}}$, by Assumption $4, \alpha\left(\gamma^{*}, \gamma^{*}\right)<\alpha\left(\gamma_{\mathrm{C}}, \gamma_{\mathrm{P}}\right)$. Therefore, it must be that $\gamma^{*} \geq \gamma_{C}>\gamma_{\mathrm{P}}$. But then it follows from Assumption 1 that $\mathrm{g}_{\text {parl }}=\phi\left(\gamma^{*}, \gamma^{*}\right)$ $>\phi\left(\gamma_{C}, \gamma_{\mathrm{P}}\right)=\mathrm{g}_{\text {pres }}$. This contradicts our assumption that $\mathrm{g}_{\text {parl }} \leq \mathrm{g}_{\text {pres }}$. Thus, it follows that $\mathrm{g}_{\text {parl }}>\mathrm{g}_{\text {pres }}$, even if $\gamma_{\mathrm{P}}=\gamma_{\ell}$ and, hence, $\mathrm{g}_{\text {parl }}>\mathrm{g}_{\text {pres }} \geq \mathrm{g}^{*}$ as claimed.

Two remarks are in order. First, in our description of the parliament, representatives are elected to implement very different agendas (public expenditures in their own districts); furthermore, we abstract from lobbying costs and procedures under the two systems. Introducing other elements to our parliamentary model-such as party discipline, which is common to parliamentary democracies - may change our inefficiency result. Second, in our model, the higher level of spending in the parliamentary system is not necessarily associated with a distribution of representatives with a higher propensity to spend. That is, while the model predicts that $\gamma^{*}>\gamma_{P}$ under quite general assumptions, predictions regarding the relationship between $\gamma^{*}$ and $\gamma_{\mathrm{C}}$ require additional assumptions. For example, if $\mathrm{N}$ is large and Assumptions 5 and 6 hold, it follows that $\gamma^{*}=\gamma_{\mathrm{C}}=\gamma_{\mathrm{h}}$.

Example 2 (Term Limits and Strategic Delegation): In this extension, we consider a dynamic version of the model in Section II. Our aim here is to analyze the welfare effects of imposing term limits on representatives. The public support for term limits is at first glance puzzling, because a decision-theoretic approach to the issue suggests that term limits are at best unnecessary and are potentially harmful. To see that term limits are unnecessary, we note that voters can always choose not to reelect an incumbent. Term limits are potentially harmful because they deprive voters of the opportunity to reelect representatives with specific human capital (gained through experience), force voters to dismiss representatives who have already been selected to have beneficial characteristics, and lessen the incentives for incumbents to maintain their reputations. (These arguments are made 
in Becker 1990.) Moreover, term limits may cause potential representatives to seek other careers. Thus, any case for term limits has to be based on strategic considerations.

In strategic models, it can be beneficial for all voters to agree to reduce their set of future choices. (See Dick and Lott 1993, where an influence approach to this problem is explored.) In this sense, the models in Sections I and II are particularly promising. In those models, all voters gain by restricting the set of candidates' types to a smaller interval than $\left[\gamma_{\ell}, \gamma_{h}\right]$. There are two simple versions of these models which do imply that term limits are beneficial. One approach, based on the model in Section I, relies on the assumption that lobbying ability (i.e., $\gamma_{\mathrm{C}}$ ) is increasing in seniority. If this is the case, it is straightforward to check that voter welfare is higher if term limits are in force. An alternative, slightly more complicated approach can be developed based on the model in Section II. Here, the argument is based on selection. Without term limits, voters can screen representatives based on observed past behavior and selectively reelect those representatives who have favorable types. We give one simple version of this formulation which shows that, indeed, restricting term length can be socially beneficial in this case. The essence of this version is that when voters make decisions about representatives, the representatives' types are not known with certainty. In a world without term limits, then, as voters learn the types of their representatives, voters have an incentive to not reelect incumbents whose types are too low (i.e., below $\gamma_{h}$ ). Offsetting this incentive is the feature that it takes time to learn the types of the representatives and the potential advantages of incumbency in the budgetary process. We take a step toward analyzing these incentives.

We develop a finite horizon, dynamic, stochastic version of the model in Section II. To simplify the analysis, we eliminate the president from consideration and consider only a two-period model.

We assume that voters do not know the types of the representatives at the time of elections, but that each representative knows the types of the other representatives at the time that budgets are 
adopted. The types of the representatives are either $\gamma_{\ell}$ or $\gamma_{h}$, where we assume that $\gamma_{\ell}=0$ and $\gamma_{h}>$ 1. At the beginning of the first period, voters elect representatives, and at the beginning of the second period, voters either reelect their incumbent or elect a new representative. The probability that a representative is of type $\gamma_{\mathrm{h}}$ is $0<\mathrm{p}<1$. Once representatives are elected, they play the bargaining game in Section II, except that there is no president in the game. Preferences of voters are as given in Section II:

$$
\mathrm{U}_{\mathrm{i}}=\mathrm{f}\left(\mathrm{g}_{\mathrm{i}}\right)-\mathrm{T}_{\mathrm{i}}
$$

where $\mathrm{f}$ is strictly concave. To simplify the exposition, we assume that the status quo level of spending is zero, as is the efficient level. Specifically, we assume that $\mathrm{f}^{\prime}(0)=1$. Finally, we consider only symmetric equilibria.

The voters in district i make their decisions about reelecting incumbents based only on the inferences they can draw about their representatives' types from observed spending decisions in period 1 (which depend on both the type of the proposer and the types of the representatives). Given these period 1 outcomes, voters form posterior beliefs about the types of their representatives and make their reelection decisions optimally, given these posterior beliefs. We study perfect Bayesian equilibrium in this setting.

Consider the equilibrium of this game with term limits. In this situation, voters are prevented from reelecting incumbents, so that the congress in the first period faces a static problem. Let $\mathrm{K}_{\mathrm{t}}$ be the number of representatives who have type $\gamma_{h}$ in period $t$, and let $\gamma_{t}^{*}$ denote the type of the proposer.

In period 1 , if the proposer's type is $\gamma_{1}^{*}=0$, the proposer's dominant strategy is to propose a spending level of zero in all districts. Because the status quo level of spending is zero, it follows that, regardless of the types of representatives, spending levels in all districts are zero. Similarly, if $\mathrm{K}_{1}<(\mathrm{N}+1) / 2$, then spending levels in all districts are zero, because all representatives with type $\gamma=$ 
0 will always vote against any positive spending. However, if $\gamma_{1}^{*}=\gamma_{h}$ and $K_{1} \geq(N+1) / 2$, the proposer will choose a spending level $\mathrm{g}$ in the proposer's district and spending levels $\mathrm{G}$ in the districts of $(\mathrm{N}-1) / 2$ other representatives whose types are $\gamma_{\mathrm{h}}$ to solve the problem

$$
\max _{\mathrm{g}, \mathrm{G}} \gamma_{\mathrm{h}} \mathrm{f}(\mathrm{g})-(\mathrm{g} / \mathrm{N}+\mathrm{G}(\mathrm{N}-1) / 2 \mathrm{~N})
$$

subject to

$$
\gamma_{\mathrm{h}} \mathrm{f}(\mathrm{G})-(\mathrm{g} / \mathrm{N}+\mathrm{G}(\mathrm{N}-1) / 2 \mathrm{~N}) \geq 0
$$

Here, as part of our symmetry assumption, we assume that if $\mathrm{K}_{1}>(\mathrm{N}+1) / 2$, the proposer picks districts at random from among those with $\gamma=\gamma_{h}$ to be in the winning coalition. Let $g^{*}$ and $G^{*}$ represent the solution to the proposer's problem.

Let $A_{t}$ denote the event that in period $t, \gamma_{t}^{*}=\gamma_{h}$ and $K_{t} \geq(N+1) / 2$, and let $\pi=P\left(A_{t}\right)$. Notice that with term limits, it follows that $\mathrm{P}\left(\mathrm{A}_{1}\right)=\mathrm{P}\left(\mathrm{A}_{2}\right)$. In symmetric equilibria, it follows that given $\mathrm{A}_{1}$ (and only $A_{1}$ ), the probability that the proposer is from district $\mathrm{i}$ is $1 / \mathrm{N}$ and the probability that district $\mathrm{i}$ is in the winning coalition is $(\mathrm{N}-1) / 2 \mathrm{~N}$. Thus, given $\mathrm{A}_{1}$ (and only $\mathrm{A}_{1}$ ), it follows that the distribution of period 1 outcomes is given by the following.

- $\quad$ With probability $1 / \mathrm{N}$, spending in district $\mathrm{i}$ is $\mathrm{g}^{*}$.

- With probability $(\mathrm{N}-1) / 2 \mathrm{~N}$, spending in district $\mathrm{i}$ is $\mathrm{G}^{*}$.

- With probability one, taxes in district $\mathrm{i}$ are $\left(\mathrm{g}^{*}+(\mathrm{N}-1) \mathrm{G}^{*} / 2\right) / \mathrm{N}$.

It follows that the period 1 expected utility of voters, given $A_{1}$, is given by

$$
\mathrm{Z} \equiv \mathrm{E}\left(\mathrm{U} \mid \mathrm{A}_{1}\right)=\left[\mathrm{f}\left(\mathrm{g}^{*}\right) / \mathrm{N}+\mathrm{f}\left(\mathrm{G}^{*}\right)(\mathrm{N}-1) / 2 \mathrm{~N}-(\mathrm{g} / \mathrm{N}+\mathrm{G}(\mathrm{N}-1) / 2 \mathrm{~N})\right]
$$

Note that because $\mathrm{f}$ is strictly concave with $\mathrm{f}^{\prime}(0)=1$, it follows that $\mathrm{Z}<0$.

When term limits are in place, period 2 is simply an independent draw of period 1 and, hence, it follows that overall expected utility is given by 


$$
\begin{aligned}
\mathrm{EU}_{\text {term }} & =\pi\{\mathrm{Z}+\beta[\pi \mathrm{Z}+(1-\pi) 0]\}+(1-\pi)\{0+\beta[\pi \mathrm{Z}+(1-\pi) 0]\} \\
& =\pi\left\{\mathrm{Z}+\beta\left[\mathrm{P}\left(\mathrm{A}_{2} \mid \mathrm{A}_{1}\right) \mathrm{Z}+(1-\pi) 0\right]\right\}+(1-\pi)\{0+\beta[\pi \mathrm{Z}+(1-\pi) 0]\}
\end{aligned}
$$

where the last equality holds, because with term limits, $\mathrm{P}\left(\mathrm{A}_{2} \mid \mathrm{A}_{1}\right)=\mathrm{P}\left(\mathrm{A}_{2}\right)=\pi$.

We turn now to the game without term limits. In this game, we show that the following is an equilibrium: The voters in district $\mathrm{i}$ reelect the incumbent if spending levels in period 1 in their district are either $\mathrm{g}^{*}$ or $\mathrm{G}^{*}$ as given above, and voters do not reelect incumbents otherwise. Beliefs are updated in the obvious way. If spending in their district is either $\mathrm{g}^{*}$ or $\mathrm{G}^{*}$, voters (correctly) infer that the type of their representative is $\gamma_{h}$, while if spending is zero, either in their district only or overall, voters' posteriors are the same as their priors. The outcomes of the bargaining game within the congress are the same as in the static game given above. Given the voters' strategies, we need to check that the representatives have no incentive to deviate. The only deviation of interest is one in which a representative of type $\gamma_{\ell}$ is a member of the winning coalition and spending levels in that representative's district are either $g$ (if that representative is the proposer) or $\mathrm{G}$ if that representative is a member of the winning coalition. Suppose that the representative is a member of the winning coalition. Deviation to a pretense of type $\gamma_{\mathrm{h}}$ gives a current period payoff of

$$
-(\mathrm{g} / \mathrm{N}+\mathrm{G}(\mathrm{N}-1) / 2 \mathrm{~N})
$$

and a next period payoff of, at most, zero. Voting against the proposal gives a current-period payoff of zero for sure and, at worst, a payoff in the next period of

$$
-\beta(\mathrm{g} / \mathrm{N}+\mathrm{G}(\mathrm{N}-1) / 2 \mathrm{~N})
$$

Because $\beta<1$, it follows that the deviation is not profitable.

To calculate the equilibrium payoffs to the voters, first note that first-period payoffs are exactly as in the game with term limits, given the strategies proposed. If spending is zero (i.e., if $\mathrm{A}_{1}$ 
does not occur) in period 1 (which occurs with probability $1-\pi$, given our choice of strategies), the distribution of outcomes in period 2 is identical to the distribution in the case with term limits. To calculate the payoffs in period 2 if $\mathrm{A}_{1}$ does occur, note that because all the representatives in the winning coalition in period 1 (i.e., those whose districts receive positive spending in period 1) are reelected, the probability (conditional) that $\mathrm{K}_{2} \geq(\mathrm{N}+1) / 2$ is one. It follows that without term limits, $\mathrm{P}\left(\mathrm{A}_{2} \mid \mathrm{A}_{1}\right)=\mathrm{P}\left(\gamma_{2}^{*}=\gamma_{\mathrm{h}} \mid \mathrm{A}_{1}\right)>\pi$. Thus, expected payoffs with no term limits are given by

$$
\begin{aligned}
\mathrm{EU}_{\text {noterm }} & =\pi\left\{\mathrm{Z}+\beta\left[\mathrm{P}\left(\mathrm{A}_{2} \mid \mathrm{A}_{1}\right) \mathrm{Z}+(1-\pi) 0\right]\right\}+(1-\pi)\{0+\beta[\pi \mathrm{Z}+(1-\pi) 0]\} \\
& <\pi\{\mathrm{Z}+\beta[\pi \mathrm{Z}+(1-\pi) 0]\}+(1-\pi)\{0+\beta[\pi \mathrm{Z}+(1-\pi) 0]\}=\mathrm{EU}_{\text {term }}
\end{aligned}
$$

because $\mathrm{P}\left(\mathrm{A}_{2} \mid \mathrm{A}_{1}\right)>\pi$ without term limits and $\mathrm{Z}<0$.

We summarize with the following proposition.

Proposition 6: Expected welfare is higher when term limits are in place (and expected spending is lower).

In this result, we have maintained the Baron and Ferejohn assumption that the proposer is chosen at random from the elected representatives. A natural alternative to this assumption is that the probability that a given representative is chosen as the proposer is increasing in seniority. If we adopt this assumption here and say that the proposer is chosen at random from among those representatives with maximum seniority, it follows that the conclusion of Proposition 6 still holds, because under this scenario, $\mathrm{P}\left(\mathrm{A}_{2} \mid \mathrm{A}_{1}\right)$ is even higher. Using this fact in equation (39) gives the desired result.

\section{Conclusion}

An extensive literature in public economics and political economy argues that the details of political institutions matter for economic outcomes. This paper is very much a part of this tradition. 
We show that voting systems in which representatives represent distinct districts can lead to inefficient aggregate outcomes. In this setting, a president who is elected at large plays a central role in limiting (and perhaps eliminating) these inefficiencies. This framework is amenable to an analysis of a variety of institutional arrangements. Examples include the two analyzed here in Section III: comparisons of parliamentary and presidential systems and the value of term limits. Of course, numerous other examples not included for reasons of space are also possible. These include at-large voting for the congress and a presidential line item veto (both of which would reduce inefficiency in our simple, stark model). A more interesting example concerns the use of tax bidding arrangements for the distribution of spending that has both local and global components. Here, local districts are required to bid for the location of (for example) a military base in their district by offering to pay higher-than-average tax rates. (Details are available from the authors on request.) 
Notes

${ }^{1}$ See David W. Brady (1993), Timothy J. Feddersen (1990), Daniel Ingberman and John Villani (1993), Ingberman and Howard Rosenthal (1994), John Leonard (1991), David R. Mayhew (1991), David Menefee-Libey (1991), Mark P. Petracca (1991), and Jason A. Thurber (1991).

${ }^{2}$ Some readers may be concerned that voters in each district are identical, but that representatives' types may not coincide with those of the voters. One way of addressing this concern is to introduce heterogeneity within a district. Heterogeneity introduces additional complexity in the voting that we want to abstract from, but, under the appropriate conditions, our main results are robust to these modifications.

${ }^{3}$ An alternative model of public goods production would have only global public goods - formally, that spending levels in different districts are perfect substitutes for one another. In that case, the conclusion that the outcome is efficient when the equilibrium is interior in Proposition 1 still holds. However, the conclusion that there is split-ticket voting in equilibrium does not hold.

${ }^{4} \mathrm{~A}$ further way to counteract problems with efficiency is to introduce another dimension to the type space of the representatives corresponding to overall ability to restrain spending in other districts. (Note here that our formulation is consistent with $\partial \phi_{j} / \partial \gamma_{n}<0$ for $j \neq n$.) In that case, there is a public goods problem in choosing a representative of this type, however, since all districts benefit from such a choice. 


\section{REFERENCES}

Alesina, Alberto; Fiorina, Morris; and Rosenthal, Howard. "Why Are There So Many Divided Senate Delegations?" Working Paper 3663, National Bureau of Economic Research, 1991.

Alesina, Alberto and Rosenthal, Howard. "Partisan Cycles in Congressional Elections and the Macroeconomy.” American Political Science Review, June 1989, 83 (2), pp. 373-98.

“A Theory of Divided Government." Econometrica, November 1996, 64, pp. 1311-42.

Baron, David P. "Government Formation and Endogenous Parties." American Political Science Review, March 1993, 87 (1), pp. 34-47.

Baron, David P. and Ferejohn, John. "Bargaining in Legislatures." American Political Science Review, 1989, 83, pp. 1181-206.

Becker, Gary. "Reforming Congress: Why Limiting Terms Won't Work." Business Week, August 6, 1990.

Brady, David W. "The Causes and Consequences of Divided Government: Toward a New Theory of American Politics?” American Political Science Review, March 1993, 87 (1), pp. 189-94.

Coughlin, Peter J. “Majority Rule and Election Models.” Journal of Economic Surveys, 1990, 4 (2), pp. $157-88$.

Deering, Christopher and Smith, Steven. Committees in Congress. Washington, D.C.: CQ Press, 1990.

Dick, Andrew R. and Lott, John R. Jr. "Reconciling Voters' Behavior with Legislative Term Limits.” Journal of Public Economics, January 1993, 50, pp. 1-14.

Feddersen, Timothy J. "The Anomaly of Split Senate Delegations: A Resource Allocation Model." Working Paper, 1990. 
Fershtman, Chaim and Judd, Kenneth L. "Equilibrium Incentives in Oligopoly." American Economic Review, December 1987, 77, pp. 927-40.

Fershtman, Chaim and Kalai, Ehud. "Unobserved Delegation." Working Paper, Tel Aviv Sackler Institute of Economic Studies, 1993.

Fiorina, Morris P. "Divided Government in the States." Political Science and Politics, December 1991, pp. 646-50.

Ingberman, Daniel and Rosenthal, Howard. "Median Voter Theorems for Divisible Governments." Working Paper, Washington University, 1994.

Ingberman, Daniel and Villani, John. "An Institutional Theory of Divided Government and Party Polarization.” American Journal of Political Science, May 1993, 37 (2), pp. 429-62.

Jacobson, Gary C. The Electoral Origins of Divided Government. Boulder, Colo.: Westview Press, 1990.

. "Explaining Divided Government: Why Can’t Republicans Win the House?" Political Science and Politics, December 1991, pp. 640-43.

Leonard, John. "Divided Government and Dysfunctional Politics." Political Science and Politics, December 1991, pp. 651-53.

Mayhew, David R. "Divided Party Control: Does it Make a Difference?" Political Science and Politics, December 1991, pp. 637-40.

Menefee-Libey, David. "Divided Government as Scapegoat." Political Science and Politics, December 1991, pp. 643-46.

Mueller, Dennis C. Public Choice II: A Revised Edition of Public Choice. Cambridge: Cambridge University Press, 1989.

Persson, Torsten and Tabellini, Guido. Macroeconomic Policy, Credibility and Politics. New York: Harwood Academic, 1990. 
. "Representative Democracy and Capital Taxation." Journal of Public Economics, September 1994, 55, pp. 53-70.

Petracca, Mark P. "Divided Government and the Risks of Constitutional Reform.” Political Science and Politics, December 1991, pp. 634-37.

Reed, W. Robert and Schansberg, D. Eric. "An Analysis of the Impact of Congressional Term Limits." Economic Inquiry, 1994, 32, pp. 79-91.

Rogoff, Kenneth. "The Optimal Degree of Commitment to an Intermediate Monetary Target." Quarterly Journal of Economics, 1985, 100, pp. 1169-90.

Thurber, James A. "Representation, Accountability, and Efficiency in Divided Party Control of Government.” Political Science and Politics, December 1991, pp. 653-57.

Zupan, Mark A. "An Economic Explanation for the Existence and Nature of Political Ticket Splitting." Journal of Law and Economics, October 1991, 34, pp. 343-69. 